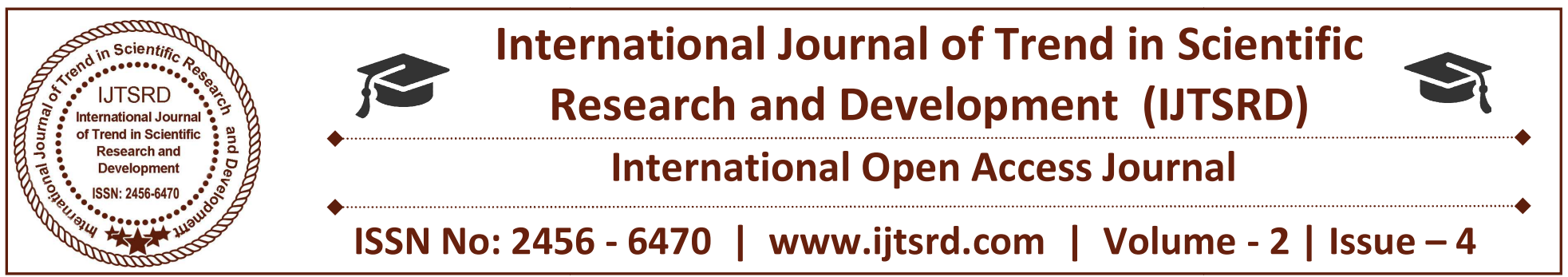

\title{
Pointers, Problems and Prospects of FMCG in Rural Market
}

\author{
Dr. M. Rajiakodi \\ Dean, College Development \\ Council, M. K. University, \\ Madurai, Tamil Nadu, India
}

\author{
Dr. R. Menaka \\ Assistant Professor, Department of \\ Management Studies (DDE), \\ M. K. University, \\ Madurai, Tamil Nadu, India
}

\author{
V. Ganesh Prasad \\ Research Scholar, \\ M. K. University, \\ Madurai, Tamil Nadu, India
}

\begin{abstract}
The Indian rural market with its vast size and demand base offers a huge opportunity that companies cannot afford to ignore. The Fast Moving Consumer Goods (FMCG) sector is a corner stone of the Indian economy. This segment touches every aspect of human life. The FMCG producers now understand that there is a lot of opportunity for them to enter into the rural market. The sector is eager about escalating rural population whose incomes are rising and which is prepared to spend on goods designed to improve life style. This paper provides information about the growth of FMCG industry in rural market of India with growing awareness and brand consciousness among people across rural area of India and how the rural markets are witnessing significant growth. It portrays the pointers prevail in the rural marketing, explaining the problems with the prospects, rural marketing strategies, problems exists in rural marketing.
\end{abstract}

Keywords: FMCG, Rural Market, Brand, Marketers, Strategies

\section{INTRODUCTION}

With a population of over one billion, India is one of the largest economies in the world in terms of purchasing power and consumer spending. The fastmoving consumer goods (FMCG) the fourth largest sector in Indian economy is an important contributor to India's GDP growth. FMCG industry primarily deals with the production, distribution and marketing and popularly named as Consumer Packaged Goods. Items in this category include all consumables people buy at regular intervals. The prices of the FMCG are low and profits earned are more dependent upon the volume sales of the products. This sector which primarily operates on low margins and strength lies in the strong presence of distribution network, stiff competition between the systematized and disorganized sector, and the strong presence of multinational firms.

The Indian rural market with its vast size and demand offers great opportunity to marketers. Our nation is classified in and around 450 districts and approximately 6, 30,000 villages. The growth of the FMCG sector, which primarily includes food and beverages, personal care and household care, lies in the rural segments. Rural consumption growth has outpaced urban consumption with the increase in percentage in monthly per capita expenditure in rural markets surpassing its urban counterparts over the past five years. The FMCG industry in India has grown rapidly over the last decade, predominantly on account of increasing income levels and changing lifestyle of Indian consumers. Several government measures such as GST Bill, Food Security Bill and FDI in retail sector are expected to have a significant positive impact on the country's FMCG sector in the coming years. Thus the paper traces out the FMCG situation in rural market, focussing on the problems and challenges and provides a forum for future prospects.

\section{POINTERS}

Distribution channels play a pivotal role in marketing by performing a number of vital distribution functions. The major area of concern for companies is 
to make their products available in the remotest corners of the villages in the country. This goal is not easy to achieve. The major companies are incurring huge costs to make their products available in the rural outlets. Firms rely mostly on their marketing channels to generate customer satisfaction, and to achieve differentiation over competition. As Basu Purba suggested that the lifestyle of rural consumers is changing. "Rural Indian market and the marketing strategy has become the latest marketing buzzword for most of the FMCG majors" (33). Indian FMCG market has been divided for a long time between the organized sector and the unorganized sector. FMCG market remains highly fragmented with roughly half the market going to unbranded, unpackaged homemade products. The rural market offers a big attraction to marketers. It is estimated that there are over a million market intermediaries' distributers, super-stockists, wholesalers, stockists, transporters and retailers who are involved in the distribution of a variety of consumer goods all over the country.

Marketing in developing countries like India have often been borrowed from western world. Concepts like brand identity, customer relationship management, marketing mix, consumer behaviour process, segmentation, targeting and positioning, etc. The relevant issues in the markets are uniqueness of the rural consumer individuality and the distribution of infrastructure in rural areas. Halan in his work "Rural Marketing is a Different Ballgame" has discussed the companies assumption that "rural markets are more price sensitive version of urban markets, is half wrong, as prices are important, but value is even more so" (60). Rural marketers own certain special problems, but the following were found to be important from the marketing point of view: "distribution and logistics, transport and handling, location and degree of concentration of demands, dealers' attitudes and motivation, consumer motivation and buying behaviours, transmission media and impact" (Singaravelu 26). Thus, the rural market bristles with many problems and to achieve a firm footing a marketer has to grasp these problems and provide innovative solutions to them.

Brand awareness is the amount of familiarity among consumers about the life and accessibility of the brand. Brand identification is the ability of customer to recognize prior understanding of brand when they are asked questions about that brand. Brand recall is the potential of customer to recover a brand from his/her remembrance when given the product class/category. The consumers recognizing and recalling the brands depend on awareness and influences preferences.

Consumer preferences are defined as the subjective to characters tastes, as measured by utility of various bundles of goods. Ability to purchase goods does not determine a consumer's likes or dislikes. The individual consumer has a set of preferences and values whose determinations are outside the realm of economics. They are no doubt reliant upon culture, education, and individual tastes, among the excess of other factors. If an individual purchases particular goods, then the opportunity cost of that purchase is the forgone goods the consumer could have bought instead.

Hoyer and Brown through their studies on effects of brand awareness on choice for repeat purchase of product revealed that "the core of brand equity lies in the construct of brand awareness. Brand equity occurs when the consumer has a high level of awareness and familiarity with the brand and holds some strong, favourable and unique associations in memory" (141). Repeat purchase then, is a function of the functional utility and image utility of the brand.

\section{PROBLEMS}

The peculiarity of the rural markets and rural consumers pose challenges to the marketers in reaching them effectively. While making out a case for opportunities that are rapidly developing in rural markets, one should not underrate the several daunting problems in planning for growth. There are many challenges like Counterfeiting, Poor Supply Chain Infrastructure, Multiple Micro-markets, Fragmented Retail Landscape, Large Geographical Expanse, Limited Cold Chain Infrastructure and Multiple Layers of Taxation ("Indian FMCG Market 2020").

Marketing activities require transportation facilities. Due to poor transportation facilities, marketers find it difficult to reach markets. In the rural areas, there are no facilities for public as well as private warehousing. Marketers face problem of storage of their goods. It is the first important step of product processing. If the packaging cost is high, it will increase the total cost of products. It is suggested that the marketers should use cheaper materials in packaging for the rural markets. Media have lots of problems in rural areas. The main 
problem of rural marketing is seasonal demand. It is because $75 \%$ of rural income is also seasonal. Rural marketing depends upon the demand of rural people and demand depends upon income and consumer behaviour. Per capita income is lower in rural areas compared to those in urban areas. Again, the distribution of rural income is highly skewed, since the land holding pattern, which is basic asset, it is skewed. The literacy rate is low in rural areas compared to urban areas. This again leads to the problem of communication for promotion purpose.

Print medium becomes ineffective and to an extent irrelevant in rural areas since its reach is poor. An effective distribution system requires different levels of shopkeeper, wholesaler or preferred dealer, distributor or stockiest at district level and companyowned depot or shipment distribution at state level. The presence of too many tiers in the supply system increases the cost of distribution. While rural marketing offers a challenging career, a rural sales person should require certain qualifications and specialized talent to deal with rural consumers. Culture is a system of shared values, beliefs and perceptions that influence the behaviour of consumers. There are different groups based on religion, caste, occupation, income, age, education and politics and each group exerts influence on the behaviour of people in villages.

There are numerous difficulties confronting the effort to fully explore rural markets. The concept of rural markets in India is still in mounting shape, and the sector poses a multiplicity of challenges. Distribution costs and non-availability of retail outlets are foremost problems faced by the marketers. The sole consumption patterns, tastes, and needs of the rural consumers should be analyzed at the product arrangement stage so that they match the needs of the rural people. Therefore, marketers need to identify with the social dynamics and approach variations within each village though nationally it follows a consistent pattern.

\section{PROSPECTS}

Rural India will make India to achieve its macroeconomic objectives by providing a wide range of consumers. The largest population in rural areas provides more opportunities in rural marketing. Rural Market, Rural consumption of FMCG products has outpaced urban consumption. Leading companies in the FMCG sector have a strong distribution network in rural India and are benefitting from the contribution of technological advances such as internet and better logistics services. As Indian consumers become increasingly exposed to global products, their demand for innovative products has been increasing.

With an emergence of India as a strong regional economy, domestic and multinational FMCG players can leverage India as a strategic sourcing hub for costcompetitive products to cater to international markets. Inorganic Growth Strategies for a Wider Footprint Companies are entering into partnerships that will help them to cater to the market, and improve their distribution networks and skills to deliver to the last mile. Most of the household and personal care products sold in India still have low market penetration in rural and semi-rural areas. This offers a wide/opportunity for market players to tap these markets by offering low cost, small packaging products, and increases in purchasing power and disposable income. Consequent lifestyle upgrade has added a new spectrum. Accessibility of market, improvement in the road systems, linking the villages have led to a systematic product distribution system. As India depends on rural economy, the systematization of FMCG in rural market will contribute to the GDP growth of India.

\section{CONCLUSION}

In the end, it is assured that FMCG companies will have to really gain inroads in the rural markets in order to attain double digit growth targets in future. There is enormous potential and definitely there is lot of money in rural India but the smart thing would be to consider in the roadblocks as carefully as possible. With this, product and brand development cycles will need to undergo a dramatic change. The companies entering rural market must do so for planned reasons and not for premeditated gains as rural consumer is still a closed book. It is only through firm commitment that the companies can make a knock in the market. Ultimately the winner would be the one with the required resources like time and money and also with the much needed innovative ideas to tap the rural markets. The new phase of rural marketing appears to provide a great opportunity for the FMCG sectors. Marketers will need to advance new strategies to connect and communicate with a more aware and absolute consumer. The demand or prospect could be improved further if companies can change the consumer's mindset and present new generation products. Thus, we can safely suggest that the future 
drivers of growth are the rural markets for the FMCG sectors.

\section{REFERENCES:}

1. "Indian FMCG Market 2020." Assocham, TechSci Research Report. Journal of Marketing 67.3 (2016): 3-34. Web. 10 June 2018.

2. Akash, S Savalasang. "The Changing Face of FMCG Marketing in Rural Sector." International Journal of Business and Administration Research Review 1.5 (April-June, 2014): 1-5. Print.

3. Goel, Rahul. "Emerging Trends in Sales Promotions in FMCG Sector in India." International Journal of Business Administration and Management 7.1 (2017): 141- 149. Print.

4. Halan, D. "Rural Marketing is a Different Ballgame." Ind. J. Mktg. 42.11 (2003): 60-64. Web. 10 June 2018.

5. Hoyer, W. D. and Brown, S. P. "Effects of Brand Awareness on Choice for a Common, Repeat Purchase Product." The Journal of Consumer Research 17.2 (2004): 141-148. Print.

6. Kavitha T. C. "A Comparative Study of Growth, Challenges and Opportunities in FMCG of Rural
Market." Inter-science Management Review (IMR) 2.3 (2012): 23-28. Print.

7. Natasha, Saqib. "Drivers to FMCG Sector in Indian Emerging Market." International Journal of Science Technology and Management 6.2 (2017): 436- 449. Print.

8. Purba, Basu. "A Study of Brand Loyalty in India." Indian Journal Marketing 11.11 (2004): 33-37. Print.

9. Sharanya, A. M., A Study on Rural Marketing Perspective of Fast Moving Consumer Goods (FMCG). IJAR 5.3 (March 2017): 1106-1110. Web. 11 June 2018.

10. Singaravelu, K., and Chella Durai. "Distribution System on Fast Moving Consumer Goods Changes and Challenges." Asia Specific Journal of Research 1.8 (August 2013): 19-26. Print.

11. Singh, A. P. and Mukesh Kumar Sahu. "Opportunities for MNC'S (FMCG Products) in Rural Market." International Journal of Emerging Research in Management \&Technology 5.7 (July 2016): 57-59. Print. 